\title{
Ash Vaporization and Condensation During Combustion of a Suspended Coal Particle
}

\author{
C. L. Senior and R. C. Flagan \\ Department of Environmental Engineering Science, \\ California Institute of Technology, Pasadena, CA 91125
}

\begin{abstract}
The results of a theoretical study of the formation and growth of the submicron flyash aerosol around a single burning coal particle are presented. The vaporization of ash and subsequent aerosol formation near the coal particle are studied because the local combustion environment infuences these processes strongly. A mathematical model is developed that describes the transport of ash vapor and and the growth of the aerosol. The ash aerosol calculation is superimposed on an existing solution to the combustion problem. Included in the model are the effects of convective transport and of both homo-
\end{abstract}

geneous and heterogeneous condensation of the ash vapor. The results of the calculations show that refractory compounds with low surface tension, like silica, nucleate very near the coal particle's surface and produce a substantial mass loading of aerosol. The presence of the aerosol does not greatly affect the ash vaporization rate, which is primarily a function of combustion conditions. The size and amount of the submicron ash aerosol are determined by both the local combustion conditions and the ash's physical properties.

\section{INTRODUCTION}

The combustion of pulverized coal produces a submicron aerosol that has been observed both in coal-fired boilers (Markowski et al., 1980) and in laboratory combustion experiments (Neville et al., 1981; Taylor and Flagan, 1981). Considerable attention has been focused on the submicron mode of the ash aerosol, primarily because of its environmental impact; these fine particles reduce visibility in the atmosphere and may represent a human health hazard if inhaled.

The submicron aerosol is characterized by a high number concentration and mean diameter on the order of $0.1 \mu \mathrm{m}$. Less than $2 \%$ of the total mass of fly ash is contained in the submicron aerosol, but because the collection efficiency of conventional gas cleaning equipment has a minimum in this size range, the submicron aerosol comprises a significant fraction of the aerosol actually emitted to the atmosphere. In one case, for example, Markowski et al. (1980) found that $20 \%$ of the aerosol mass emitted from a pulverized coal utility boiler was in the submicron mode, even though only $1.5 \%$ of the fly ash produced during combustion was in the submicron size range.

The composition of the submicron mode is different from that of the bulk ash. The major species in ash are $\mathrm{Al}, \mathrm{Ca}, \mathrm{Fe}, \mathrm{Mg}$, and Si. Some of these elements are more concentrated in the submicron aerosol than in the bulk ash, while others are depleted with respect to the bulk ash. Laboratory combustion studies of three coals by Neville et al.(1981) showed that Mg and Fe were enriched and $\mathrm{Al}$ was depleted in the submicron aerosol. $\mathrm{Ca}$ and $\mathrm{Si}$ did not show consistent enrichment or depletion trends. Trace elements like zinc have also been found to be concentrated in the submicron aerosol (Taylor and Flagan, 1981).

The submicron aerosol is formed by vaporization of the ash during combustion followed by condensation. A vaporization-condensation mechanism can explain the differences in composition between the submicron aerosol and the bulk ash and the high aerosol number concentration. Volatility differences among the species in ash causes their enrichment or depletion in 
the submicron aerosol. Homogeneous nucleation is capable of producing a large number of very small particles that can grow by heterogeneous condensation or coagulation. A better understanding of the processes by which this aerosol is formed may lead to more effective control strategies for particulate pollutants.

To date there have been few theoretical studies of the formation of submicron aerosol from coal combustion. Desrosiers et al. (1979) modeled the diffusive transport of vapor away from a burning coal particle. Ash vapor concentrations near the particle's surface were calculated from consideration of liquid-vapor equilibrium, and the vapor was assumed to nucleate and grow in the combustion gases far from the burning coal particles. McNallan et al. (1981) modeled the homogeneous nucleation of silicon, sodium, and lead as the products of combustion cooled, assuming that the ash vapors were uniformly distributed in the product gases and that the gas temperature was uniform. Both of the two analyses neglected the influence of the local combustion environment on aerosol formation and growth. This approach may be valid for species such as $\mathrm{As}, \mathrm{Na}$, and $\mathrm{Pb}$, which remain volatile long after combustion is complete. However, the fate of refractory species such as $\mathrm{Si}, \mathrm{Ca}$, and $\mathrm{Mg}$ may be determined very near the burning coal particle, long before the product gases cool significantly. There is evidence that conditions surrounding the burning coal particle are very different from those in the bulk product gases.

The combustion process affects the transport of vapor and the growth of aerosol in two important ways. First, the mass flux due to combustion induces a bulk motion away from the coal particle. This radial convection enhances the transport of vapor from the particle's surface. Second, the combustion process alters the local gas composition and temperature. Because char combustion is exothermic, the particle temperature may be higher than that of the surrounding gas. For combustion of coal in air, particle temperatures several hundred degrees greater than the gas temperature have been measured by Mims et al. (1980) and by Mitchell and McLean (1982). In addition to a temperature gradient around a burning coal particle, there is a gas composition gradient. The combustion reaction consumes oxygen in the neighborhood of the coal particle. The gas near the particle's surface is, therefore, more reducing than the bulk gas.

Radial transport and local temperature and composition gradients can enhance the vaporization of ash. In a reducing environment, metal oxides can be reduced to the more volatile suboxide or metal species. In a study of the vaporization of silica during coal gasification and combustion, Raask and Wilkins (1965) concluded that the amount of silica vaporized could not be explained by direct vaporization, but must be due to the reduction of silica to silicon monoxide in the char. Aerosol formation and growth can be affected by the local combustion environment, too. As vapor moves away from the coal particle, it becomes supersaturated because of the gas temperature and composition gradients; this provides a strong driving force for condensation, either homogeneous or heterogeneous.

The purpose of this study is to assess the importance of the local environment of a burning fuel particle on ash vaporization and submicron aerosol formation. We develop a mathematical model that accounts for the transport of vapor, formation of aerosol by homogeneous nucleation, and growth of aerosol by condensation in the vicinity of a single burning coal particle. Our intent is not to predict quantitatively the ash vaporization rates and aerosol size distributions that result from burning coal. Instead, we wish to understand the qualitative behavior of aerosol and vapor during a single phase of the entire process, combustion. An extended example is presented to illustrate the kinds of information that this model can offer and the importance of various parameters in the problem. Silica is used to represent the ash in these calculations. It is a major component of both the bulk ash and, in some cases, the submicron aerosol. Furthermore, because of its 
refractory nature, it is more likely to be affected by the local combustion environment than some of the more volatile species found in ash.

\section{THEORETICAL ANALYSIS}

The steady diffusion of vapor from a single sphere is considered in this analysis. The vapor problem is superimposed on the solution to the quasi-steady combustion of a single burning coal particle, which provides values for the radial convective velocity and gas composition and temperature profiles around the particle at any instant. The gas is assumed to contain only trace amounts of the vapor, so the presence of vapor (and the subsequent aerosol) may be assumed to have no effect on the combustion process.

\section{Coal Combustion Model}

The aerosol calculation requires the following information about the combustion process and the environment around a burning coal particle: the combustion rate, the instantaneous gas composition profile, and the instantaneous gas temperature profile. A combustion model has been developed by Senior and Flagan (1982), based on the work of Libby and Blake (1979), to provide this information.

The local gaseous environment during combustion is described by a quasi-steady combustion model. The behavior of the gas phase is modeled as a succession of steady states, assuming that the response time of the gas is much shorter than that of the coal particle. In this way, the local environment of a single coal particle is characterized throughout the entire combustion process. A spherical coal particle is assumed to be immersed in an infinite quiescent medium. The quasi-steady treatment of the gas phase is coupled with a dynamic particle energy balance. Chemistry in the gas is assumed to be frozen. The effects of devolatilization and bulk ash on combustion are also included in the combustion model.

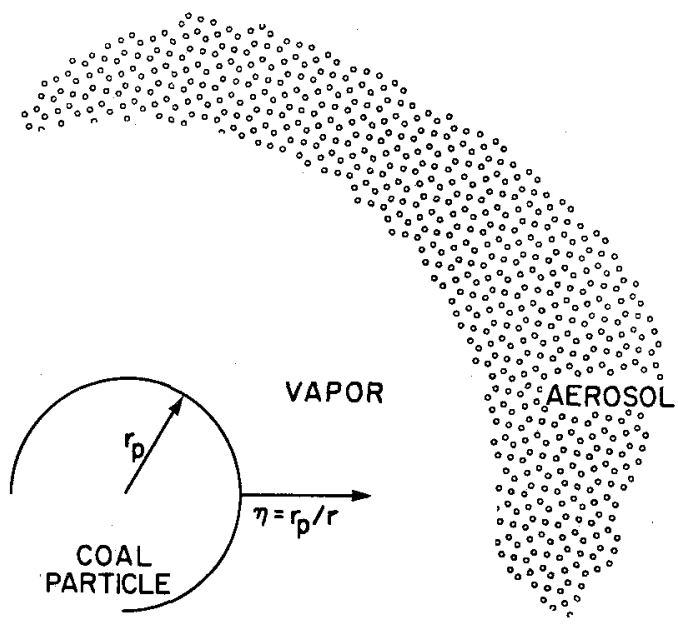

FIGURE 1. The local environment around a burning coal particle.

Radial coordinates centered on the particle are used in the analysis (Figure 1). A radial convective velocity is caused by the bulk gas motion due to combustion. At typical pulverized coal combustion conditions, the important combustion reaction is $2 \mathrm{C}+\mathrm{O}_{2} \rightarrow 2 \mathrm{CO}$ (Mulcahy and Smith, 1969). For every oxygen molecule that moves toward the surface, two carbon monoxide molecules move away from the surface. The convective velocity $u$ is proportional to the combustion rate $R$ :

$u=R / 4 \pi r^{2} c$,

where $r$ is radial position (in centimeters) and $c$ is gas concentration in moles per cubic centimeter. $R$ has units of moles per unit time.

\section{Conservation Equations}

Vapor is transported away from the particle's surface by convection and diffusion. Vapor is lost by both homogeneous and heterogeneous condensation. Particles formed by vapor condensation are transported away from the burning coal particle primarily by convection since the particle diffusivities are much less than that of the vapor. Vapor condensation represents a sink for vapor and a source for aerosol. 
Assuming the transport and growth processes to be much faster than combustion, a quasi-steady conservation equation can be written for the total volatilized ash. It will be shown later that the quasi-steady formulation is justified. The conservation equation is written in terms of $y$, the vapor species mole fraction, and $M$, the moles of aerosol per mole of gas, as

$R \frac{d}{d r}(y+M)=\frac{d}{d r}\left(4 \pi r^{2} c D \frac{d y}{d r}\right)$

where $D$ is the gas diffusivity, subject to

$$
\begin{array}{lll}
y=y_{\mathrm{p}} & \text { at } & r=r_{\mathrm{p}} \\
y=0 & \text { as } & r \rightarrow \infty, \\
M=0 & \text { at } & r=r_{\mathrm{p}} .
\end{array}
$$

(The index $p$ denotes conditions at the particle surface.) The quantity $c D$ is assumed to be constant in the region surrounding the coal particle. It has been calculated at a temperature that is the geometric mean of the particle temperature and the free stream gas temperature. For the sake of simplicity we calculate the surface partial pressure by assuming that the vapor species is in equilibrium with liquid at the particle's surface. More complicated models for the surface boundary condition (e.g., Quann and Sarofim, 1982) could be used in the framework of this analysis.

Equation (2) can be solved if the aerosol mole fraction $M$ is known. [In fact, the case of no particle formation $(M=0)$ has a simple analytic solution.] The aerosol mole fraction, which is proportional to the total volume of aerosol at any radial position, can be obtained by integrating the aerosol size distribution function:

$M=\frac{\rho}{M_{\mathrm{w}}} \int_{0}^{\infty} \frac{\pi}{6} D^{3} n(D, r) d D$,

where $\rho$ and $M_{\mathrm{w}}$ are the species density and molecular weight, respectively. The aerosol size distribution function $n$ has units of number per centimeter per mole of gas. $D$ is the particle diameter.

The aerosol size distribution function is determined using an aerosol growth equation. The change in the number of particles with position and particle size is expressed by three terms: convection (the diffusion of particles is neglected), growth by condensation, and the formation of new particles by nucleation (with nucleation rate $I ; D_{*}$ is a critical diameter explained presently):

$R \frac{\hat{c} n}{\partial r}+4 \pi r^{2} c \frac{\partial(n \dot{D})}{\partial D}=4 \pi r^{2} I \delta\left(D-D_{*}\right)$.

Particle growth by coagulation is neglected in the present analysis. The condensation growth law $\dot{D}$ is calculated for particles in the free molecule range, neglecting the Kelvin effect. Thus, the growth law becomes (Friedlander, 1977)

$\dot{D}=2 v_{\text {m }}\left(p-p_{\mathrm{e}}\right) /(2 \pi m k T)^{1 / 2}$,

where $v_{\mathrm{m}}$ and $m$ are the molecular volume and mass, respectively, of the liquid state, $k$ is the Boltzman constant, and $p$ is the species vapor pressure. The subscript e denotes equilibrium conditions.

Equation (4) can be solved easily because the growth rate [Eq. (5)] is a function of racial position but not particle size. Later in the paper we discuss the validity of the assumptions that allow such a simple form for the particle growth law. The term on the right-hand side of Eq. (4) represents the addition of new particles to the aerosol by nucleation. We assume that new particles are formed with a diameter $D_{*}$ (hence the use of the delta function). The critical diameter $D$. is a function of local temperature and saturation ratio. An average critical diameter independent of radial position is used in this analysis. This is calculated as the numberaverage critical diameter over all space.

The nucleation rate $I$ (in units of number per cubic centimeter per second) is given by Friedlander (1977) as

$$
\begin{aligned}
I= & 2 \alpha_{\mathrm{c}}\left[\frac{p}{(2 \pi m k T)^{1 / 2}}\right] \frac{p}{k T} v_{\mathrm{m}}^{2 / 3} \\
& \times\left[\frac{\sigma v_{\mathrm{m}}^{2 / 3}}{k T}\right]^{1 / 2} \exp \left[\frac{-16 \pi \sigma^{3} v_{\mathrm{m}}^{2}}{3(k T)^{3} \ln ^{2}\left(p / p_{\mathrm{e}}\right)}\right],
\end{aligned}
$$

where $\sigma$ is the surface tension of the liquid species and is assumed to be constant for a given 
calculation. The accomodation coefficient $\alpha_{\varepsilon}$ is assumed to be unity.

\section{Method of Solution}

In order to transform the problem from an infinite domain to a finite one, the conservation equations are rewritten in terms of a new independent variable $\eta=r p / r$. The method of characteristics is applied to the aerosol growth equation to derive an explicit expression for the aerosol mole fraction $M$. Finally, the ash conservation equation is solved numerically using a shooting method.

With this transformation the aerosol growth equation becomes

$\frac{-R}{r_{\mathrm{p}}} \eta^{2} \frac{\partial n}{\partial \eta}+\frac{4 \pi r_{\mathrm{p}}^{2}}{\eta^{2}} c \dot{D} \frac{\hat{c} n}{\partial D}=\frac{4 \pi r_{\mathrm{p}}^{2}}{\eta^{2}} I \delta\left(D-D_{*}\right)$

subject to the boundary conditions

$$
n(D, 1)=0, \quad n\left(D_{*}, \eta\right)=0 \text {. }
$$

Equation (7) is to be solved using the method of characteristics. The solution is found along trajectories of the size distribution function $n$; these trajectories are called characteristics and depend on initial conditions. Along a characteristic the dependent and independent variables are related by

$$
\frac{-d \eta}{R \eta^{2} / r_{\mathrm{p}}}=\frac{d D}{4 \pi r_{\mathrm{p}}^{2} c \dot{D} / \eta^{2}}=\frac{d n}{4 \pi r_{\mathrm{p}}^{2} I \delta\left(D-D_{*}\right) / \eta^{2}} \text {. }
$$

This equation can be rearranged to obtain two ordinary differential equations for $d D / d \eta$ and $d n / d \eta$. Because $\delta\left(D-D_{*}\right) d D=\delta\left(\eta-\eta_{*}\right) d \eta$, where $\eta *$ is defined as the position where a particle must nucleate in order to grow to a diameter $D$ at a radical position $\eta$, the size distribution in Equation (8) can be evaluated explicitly in terms of $\eta_{*}$ instead of $\mathrm{D}$, yielding

$n(D, \eta)=I\left(\eta_{*}\right) / c \dot{D}\left(\eta_{*}\right)$

The relationship among $\eta, \eta_{*}, D$, and $D_{*}$ is known along a characteristic from the solution to $\mathrm{Eq}$. (8).

The integral of the aerosol size distribution function must be evaluated to solve Eq. (2). Substituting Eq. (9) into the integral from Eq. (3) and changing the integration variable from $D$ to $\eta *$ we find

$M=-\frac{4 \pi r_{\mathrm{p}}^{3} \rho}{R M_{*}} \int_{1}^{\eta_{\pi} \pi} \frac{D^{3}\left(\eta_{*}\right) I\left(\eta_{*}\right)}{\eta_{*}^{4}} d \eta_{*}$

Thus the total amount of aerosol at any radial position is related simply to the nucleation rate and the growth rate. In order to obtain Eq. (10), the lower limit of the integral in Eq. (3) has been changed to $D_{*}$. For the conditions we shall consider, the critical nucleus is only a few molecules, so this change has little affect on the final numerical answer.

The method of characteristics provides an expression for the aerosol mole fraction that can be evaluated at any radial position. To complete the solution, the ash conservation equation is integrated once:

$4 \pi r_{\mathrm{p}} c D \quad d y / d r=R(y+M)-K_{v}$.

$R_{v}$ is an unknown constant of integration equal to the rate of vaporization at the particle's surface. Equation (11) is transformed to inverse radial coordinates to give

$\frac{d \bar{y}}{d \eta}=-\operatorname{Pe}\left(\bar{y}+\bar{M}-R_{\mathrm{v}} / y_{\mathrm{p}} R\right)$

subject to

$\hat{y}(1)=1$.

A tilde over a variable means that it has been normalized with respect to $y_{\mathrm{p}}$, and the Peclet number at the particle's surface is defined as

$\mathrm{Pe}=R / 4 \pi r_{\mathrm{p}} c D$

Equations (10) and (12) can be integrated from the surface of the coal particle $(\eta=1)$ to infinite radius $(\eta=0)$. A shooting method is employed to solve the system. Beginning with an initial estimate for the vaporization rate $R_{v}$, the properties at $\eta=0$ are evaluated. The system is integrated using a modified fourth-order RungeKutta scheme developed by Fehlberg (1969). If the correct value for $R_{v}$ has been used, the mole fraction of vapor will be zero at the boundary $\eta=0$. If not, a new value of $R_{\mathrm{v}}$ is chosen and the calculation is repeated. 
TABLE 1. Conditions for Computations

\begin{tabular}{llll}
\hline \multicolumn{2}{c}{ Coal Combustion } & & Ash \\
\hline particle radius & $40 \mu \mathrm{m}$ & surface tension & $300 \mathrm{dyn} / \mathrm{cm}$ \\
volume fraction ash & 0.05 & liquid density & $2.2 \mathrm{~g} / \mathrm{cm}^{3}$ \\
inclusion diameter & $2.5 \mu \mathrm{m}$ & molecular weight & $60.9 \mathrm{~g} / \mathrm{mol}^{\prime}$ \\
frec stream gas temperature & $1750 \mathrm{~K}$ & diffusivity $c D=a T+b:$ & \\
free stream gas & air & $a$ & $9.11 \times 10^{-9} \mathrm{~mol} /(\mathrm{cm} \mathrm{sec} \mathrm{K})$ \\
& & $b$ & $7.363 \times 10^{-6} \mathrm{~mol} /(\mathrm{cm} \mathrm{sec})$ \\
\hline
\end{tabular}

\section{RESULTS}

In order to examine the behavior of the model and its sensitivity to parameter variation, an example is discussed in which the ash is represented by a single species. Two aspects of the solution are important: the character of the aerosol produced and the rate of vaporization of the ash species. The influence of the ash properties and the local combustion environment on the aerosol size distribution and vaporization rate will be examined. (The conditions for the computations herein are given in Table 1.)

\section{Example: Silica Vaporization During Combustion}

Silica is chosen to represent the ash for several reasons. First, it is found in significant quantities in both the bulk ash and in the submicron aerosol (Neville et al., 1981) produced from coal combustion. Silicia is representative of a class of compounds found in ash, often called refractory oxides, that have a relatively low volatility at temperatures below $2000 \mathrm{~K}$ and yet are found to be major constituents of the submicron aerosol. Calcium oxide and magnesium oxide are two other compounds in this class. Finally, the requisite physical and thermodynamic properties for silica can be found in the literature. The latter point is not a trivial one. The present model requires equilibrium vapor pressure, liquid density, surface tension, and gaseous diffusivity for the compound of interest. Values for these properties are often difficult to obtain for high-temperature oxides.

For the present work we assume that liquid oxide on the particle's surface is in equilibrium with vapor. In a high-temperature environment such as that surrounding a burning char particle, the reduction of silica $\left(\mathrm{SiO}_{2}\right)$ to form gaseous silicon monoxide $(\mathrm{SiO})$ determines the vapor pressure of silicon-containing species (Schick, 1960). We assume that the equilibrium vaporization reaction may be written

$$
\mathrm{SiO}_{2}(\mathrm{l})+\mathrm{CO} \rightleftarrows \mathrm{SiO}(\mathrm{g})+\mathrm{CO}_{2} .
$$

The primary product of carbon combustion at high temperatures is carbon monoxide (Mulcahy and Smith, 1969). If the subsequent oxidation to carbon dioxide occurs far from the particle, the only source of $\mathrm{CO}_{2}$ near the particle is the $\mathrm{SiO}_{2}$ reaction. The $\mathrm{CO}_{2}$ partial pressure is, therefore, assumed to be equal to the $\mathrm{SiO}$ partial pressure. The equilibrium vapor pressure of silicon monoxide is given by

$p_{\mathrm{SiO}}=\left(K a_{1} p_{\mathrm{CO}}\right)^{1 / 2}$.

$K$ is the equilibrium constant calculated from the JANAF tables (Dow Chemical Co., 1971) and $a_{1}$ is the activity of the liquid silica (assumed to equal 1). Equation (14) is used to calculate the $\mathrm{SiO}$ partial pressure at the coal particle surface and to calculate the equilibrium pressure needed to evaluate the condensation flux [Eq. (5)]. Hence we assume that $\mathrm{SiO}$ vapor is oxidized to $\mathrm{SiO}_{2}$, which then condenses as liquid.

Consider a bituminous coal particle with 40 $\mu \mathrm{m}$ initial radius burning in the air that has been heated to $1750 \mathrm{~K}$. Figure 2 shows the temperature and gas composition at the particle's surface as a function of burnout for this coal particle. (Burnout is defined as the volume fraction of 


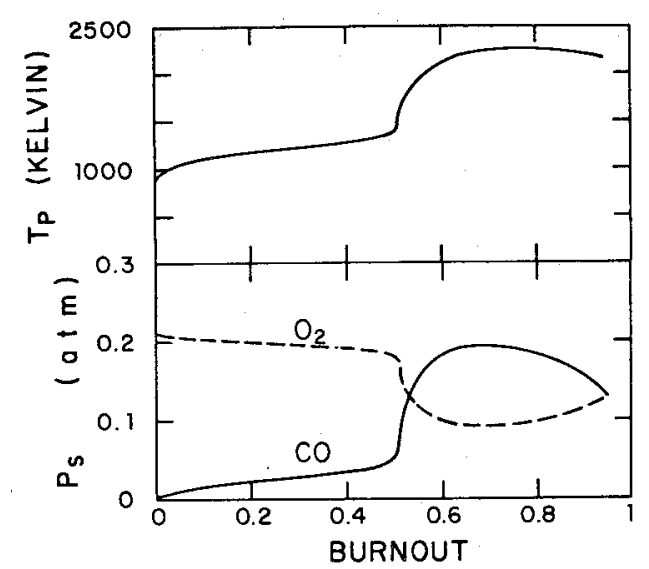

FIGURE 2. Particle temperature and gas composition (partial pressures) at the surface of a bituminous coal particle ( $40 \mu \mathrm{m}$ initial radius) burning in air with a gas temperature of $1750 \mathrm{~K}$.

carbon that has been lost by devolatilization or combustion.) During devolatilization (burnout less than about $50 \%$ ) the particle temperature is less than the gas temperature. Char combustion becomes important for burnout greater than $50 \%$. Owing to the exothermicity of the char combustion reaction, there is a rapid rise in particle temperature to $400-500$ degrees above the gas temperature. Figure 2 also shows the oxygen and carbon monoxide partial pressure at the surface. For combustion in air there is no carbon dioxide in the gas, since the gas-phase chemistry is frozen. During devolatilization the oxygen partial pressure at the surface remains relatively constant, but drops sharply when char combustion becomes important. At this point the carbon monoxide concentration increases due to combustion.

The quantities needed for the aerosol calculation are the instantaneous radial profiles of gas composition and temperature. Figure 3 shows these profiles evaluated at $64 \%$ burnout. The significant feature of these curves is that both temperature and carbon monoxide partial pressure drop sharply within about three particle radii from the surface. This results in a rapid decrease in the equilibrium vapor pressure with increasing radius, since the vapor pressure de- pends strongly on temperature and carbon monoxide partial pressure.

\section{Aerosol Formation}

The size distribution function [Eq. (9)] is inversely proportional to the condensation rate and proportional to the nucleation rate. Since the nucleation rate varies exponentially with the parameters in the system, i.e.,

$I \sim \frac{y^{2}}{T} \frac{\left(\sigma M_{\mathrm{w}}\right)^{1 / 2}}{\rho} \exp \left[-\left(\frac{M_{\mathrm{w}}}{\rho}\right)^{2}\left(\frac{\sigma}{T}\right)^{3} \frac{C}{\ln ^{2} S}\right]$,

where $S=p / p_{\mathrm{e}}$ is the saturation ratio, it should have the larger influence on the aerosol distribution. Both the ash properties (molecular weight, density, and surface tension) and the local combustion environment strongly influence nucleation rate and the resulting aerosol. The saturation ratio is a function of both local gas temperature and local gas composition, as described in Eq. (14). In the aerosol calculation, we shall use constant values for the physical properties of silica (Kingery, 1959; Smithells, 1976). In the next section the effect of the variation of physical properties is discussed.

FIGURE 3. Profiles of the gas temperature and carbon monoxide around a burning coal particle at $64 \%$ burnout.

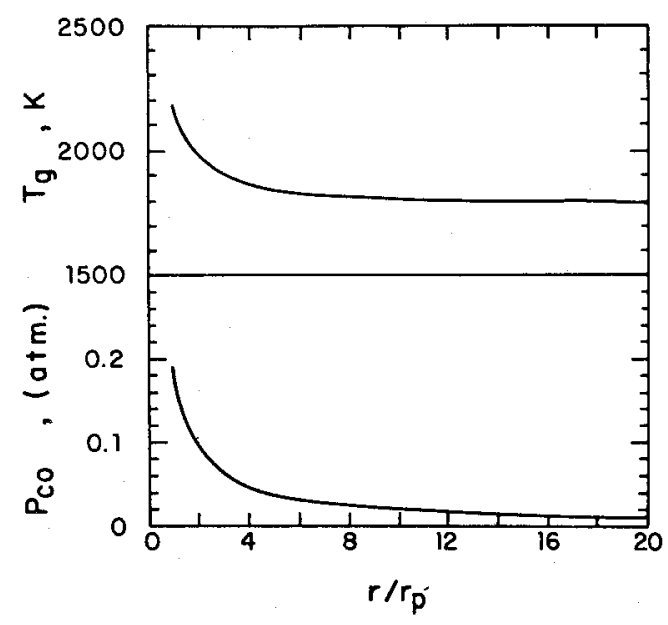




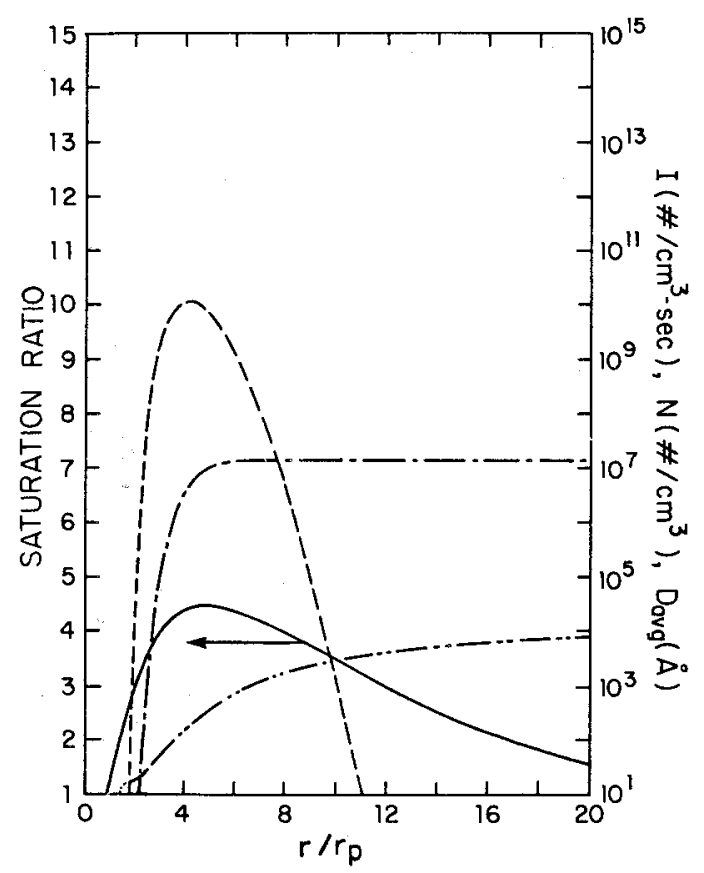

FIGURE 4. Results of the aerosol calculation for silica at $64 \%$ burnout. - - , saturation ratio; --- , nucleation rate (number per cubic centimeters per second); ---, number density (number per cubic centimeter); $-\cdots-$. average diameter (angstroms)

Figure 4 shows the results of the aerosol calculation at $64 \%$ burnout. Plotted are the radial profiles of saturation ratio and logarithms of nucleation rate, total number concentration, and average diameter. The saturation ratio rises very sharply with radial position and peaks three radii from the particle's surface. It is in this region that both the gas temperature and the carbon monoxide partial pressure are rapidly decreasing (Figure 3). The saturation ratio decreases slowly beyond three radii, for the most part because of depletion of vapor by condensation. As the saturation ratio increases, so does the nucleation rate. The number concentration also grows rapidly within three particle radii. Farther away from the particle, however, the number concentration is constant because the nucleation rate becomes too small to change the total number significantly. The average diameter increases slowly with radial position owing to condensation; it is still increasing at large radial positions.

The preceding discussion applies to a single instant in the combustion history. Local conditions change dramatically throughout the combustion, as was shown in Figure 2. In order to consider the influence of the local combustion environment on the aerosol, we shall perform the aerosol calculation at various points in the sample combustion history. Figure 5 gives the aerosol number concentration, mass loading, and average diameter as a function of burnout for several different radial positions. It is evident from all three parts of this figure that there is no vaporization or aerosol formation during devolatilization.

The number concentration (Figure 5a) increases dramatically from one to three particle radii from the particle's surface. For radical positions greater than this, there is almost no change in the total number of particles. The mass loading (Figure 5b), however, steadily increases with radial position after the total number has stopped changing, due to the growth of aerosol by condensation. Within eight particle radii of the surface, the mass loading reaches very high values. The effect of condensation can also be seen in Figure 5c, where the average aerosol diameter is plotted versus burnout. In this example, the average diameter grows larger than $0.1 \mu \mathrm{m}$ within eight particle radii from the surface.

Finally, we consider the variation of vaporization rate with combustion conditions in order to quantify the effect of local conditions and aerosol formation on vaporization. If there is no aerosol in the gas, the vaporization rate $R_{\mathrm{v} 0}$ is

$R_{\mathrm{v} 0}=R y_{\mathrm{p}} /\left(1-e^{-\mathrm{Pe}}\right)$.

Figure 6 shows the vaporization rate calculated for various values of burnout plotted against the corresponding value of $R_{\mathrm{v} 0}$. The formation and growth of the aerosol increases vaporization by less than $10 \%$ for the sample combustion history. The Peclet number at the particle's surface 


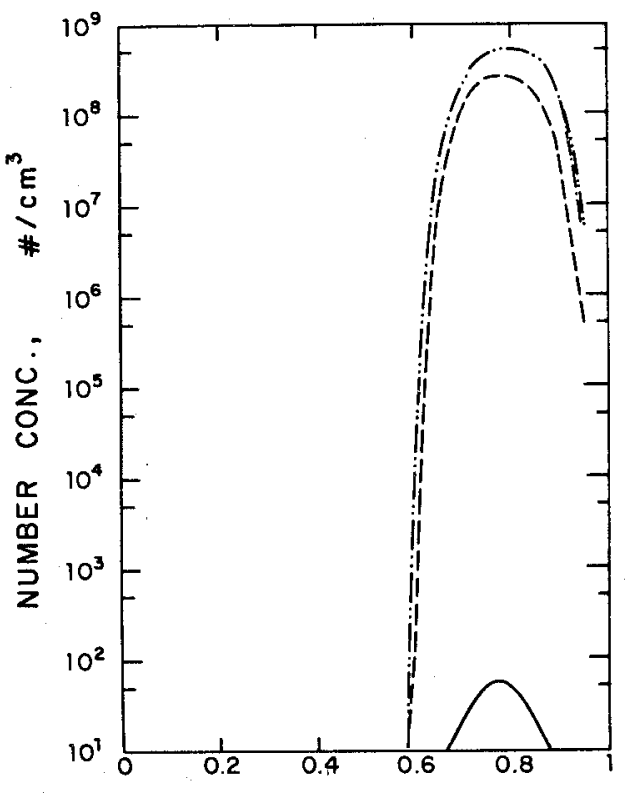

(a)

BURNOUT

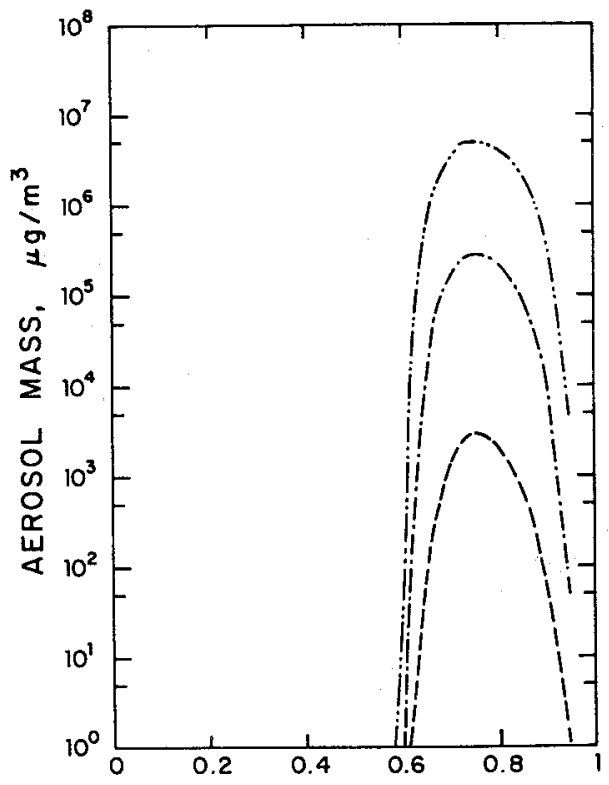

(b)

BURNOUT

FIGURE 5. Characteristics of the aerosol as a function of burnout at (-) one, (- --$)$ three, (--) five, and (-*-) eight particle radii from the surface: (a) Number concentration, (b) mass loading, and (c) average particle diameter.

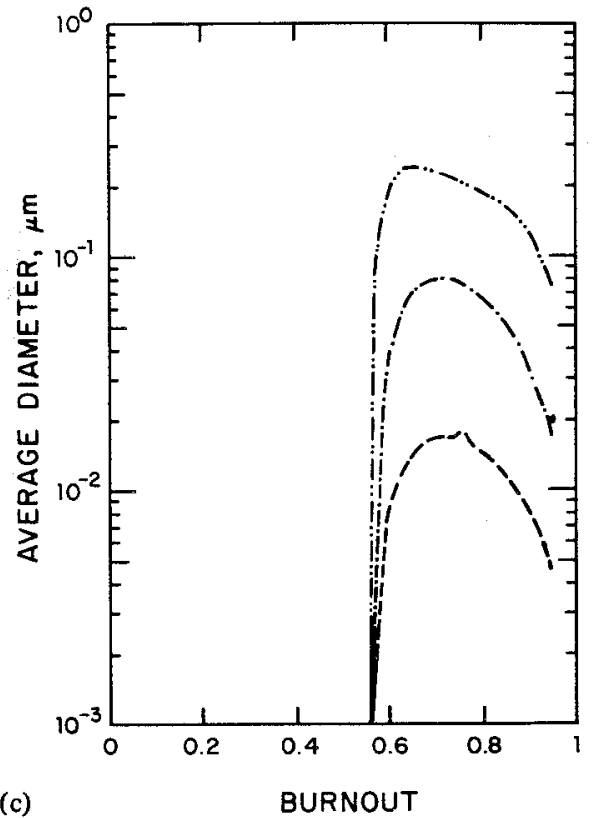

is near unity for these calculations, and therefore some of the transport of vapor from the particle's surface is by convection. The influence of the vapor concentration gradient on vaporization is somewhat damped by convection.

FIGURE 6. Effect of aerosol formation and growth on the vaporization rate.

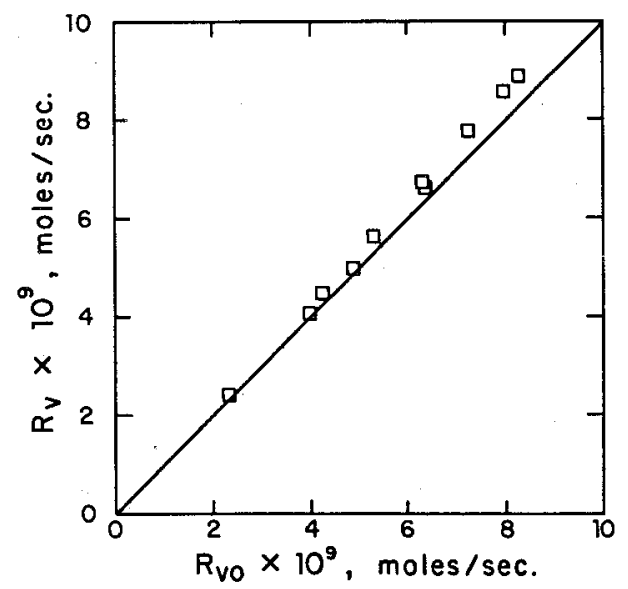




\section{Effect of Physical Properties}

The effects of ash properties on aerosol formation may be examined by considering the influence of surface tension variation. Equation (15) shows which other physical properties, e.g., molecular weight and density, have similar effects on the aerosol size distribution. The local temperature and composition profiles used are those given in Figure 3. The value of the surface tension of silica used in the previous calculation was $300 \mathrm{dyn} / \mathrm{cm}$; this value correponds to that measured by Kingery (1959) at a temperature of $1900 \mathrm{~K}$. Because of temperature variation with radial position, the surface tension of silica actually varies from 310 to $295 \mathrm{dyn} / \mathrm{cm}$.

Decreasing the surface tension produces a higher nucleation rate and number concentration. Figure $7 \mathrm{a}$ shows the calculation with a surface tension of $250 \mathrm{dyn} / \mathrm{cm}$. The peak nucleation rate and the final number concentration have increased by two orders of magnitude with only a $17 \%$ decrease in surface tension. In Figure $7 \mathrm{~b}, \mathrm{c}$ the surface tension has been increased to 350 and $400 \mathrm{dyn} / \mathrm{cm}$, respectively. High values of the surface tension suppress nucleation. A $14 \%$ increase in surface tension (Figure $7 \mathrm{~b}$ ) causes the peak nucleation rate to decrease by four orders of magnitude. At even higher values of the surface tension nucleation ceases entirely and there are essentially no particles formed.

The value of the surface tension has a profound effect on the character of the aerosol because the nucleation rate is such a strong function of surface tension. However, the vaporization rate is not strongly affect by ash properties. For the preceding cases there is only a $5 \%$ variation in vaporization rate even though the amount and size of the aerosol varies over many orders of magnitude.

\section{DISCUSSION}

Now that the results of a sample calculation have been presented, we shall examine the validity of the major assumptions that have been made in the formulation of the model. A steady conservation equation for the transport of ash
[Eq. (2)] has been superimposed on the solution to the combustion problem. In order to employ this method, the time scales for transport and aerosol growth must be much shorter than the combustion time scale. Equation (6) for the nucleation rate is derived assuming the existence of a quasi-steady state for the distribution of molecular clusters. For the theory to be valid, there must be sufficient time for the establishment of this steady state. Coagulation has been omitted from the aerosol growth equation (4) in order to simplify the analysis. We have assumed implicitly that the coagulation process is much slower than the transport and aerosol growth processes. The validity of these assumptions can be judged by comparing the time scales of various processes: combustion, convection, vapor diffusion, nucleation, and coagulation. Finally, we have used an aerosol growth law [Eq. (5)] for particles in the free molecule regime (neglecting the Kelvin effect), and we shall assess the qualitative effects of this approximation on the aerosol size distribution.

The characteristic times of the relevant processes are shown in Figure 8 at a representative point in the combustion history ( $64 \%$ burnout). Since convective velocity, vapor concentration, and aerosol number concentration change with radial position, the characteristic times are calculated as functions of radial position. The length scale used in calculating the characteristic times is the coal particle radius. The nucleation time represents the time required to establish a quasi-steady distribution of molecular clusters, as proposed by Wakeshima (1954). A range of characteristic times for coagulation is estimated from the total aerosol number and the Brownian coagulation coefficient -(Gelbard, 1978) calculated for collision between a particle of the critical size $(1 \mathrm{~nm})$ and a representative-size particle. The lower bound on the characteristic time represents collision with a $1 \mu \mathrm{m}$ particle, the upper bound with a particle of the average diameter.

The combustion time scale is much slower than any of the transport or growth time scales. Within at least $10-20$ particle radii of the coal particle, the vapor and aerosol are always in 


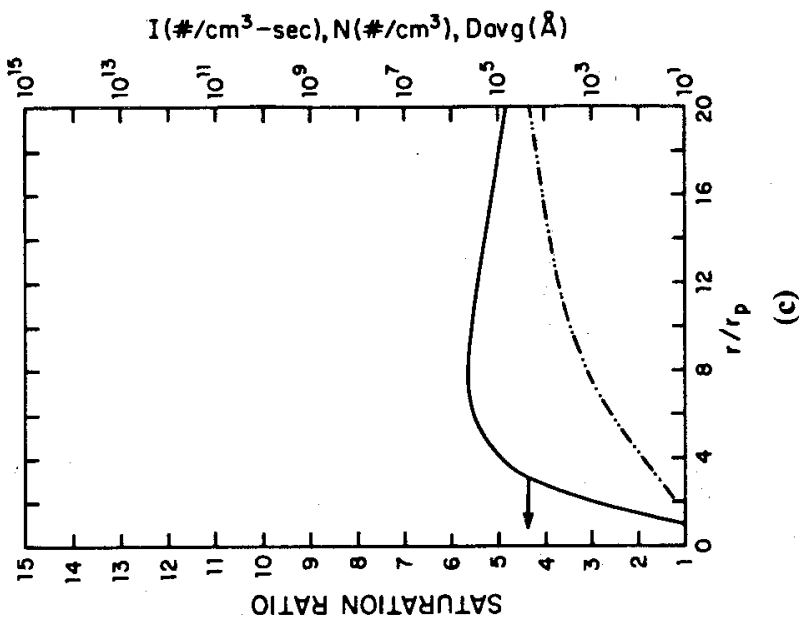

$I\left(\# / \mathrm{cm}^{3}-\mathrm{sec}\right), \mathrm{N}\left(\# / \mathrm{cm}^{3}\right)$, Dovg $(\AA)$

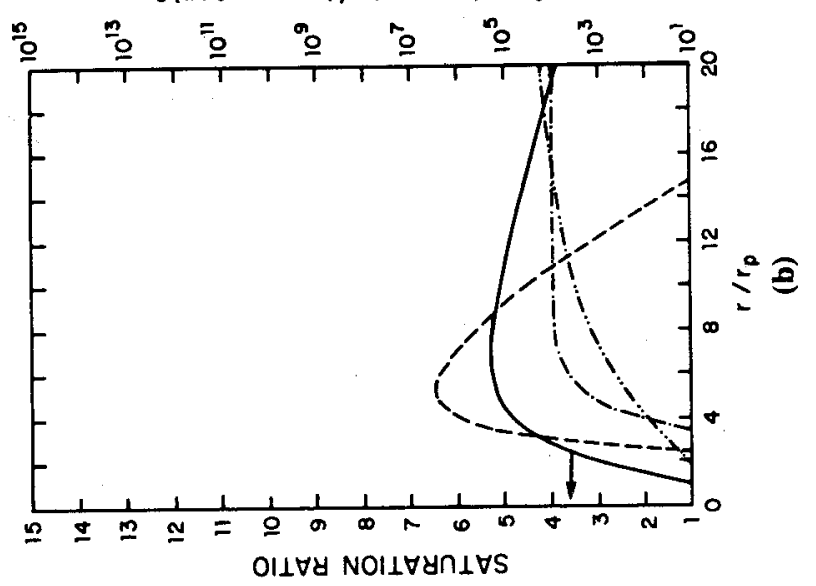

हृ

方

巳一

을

串

อิํํㄹ

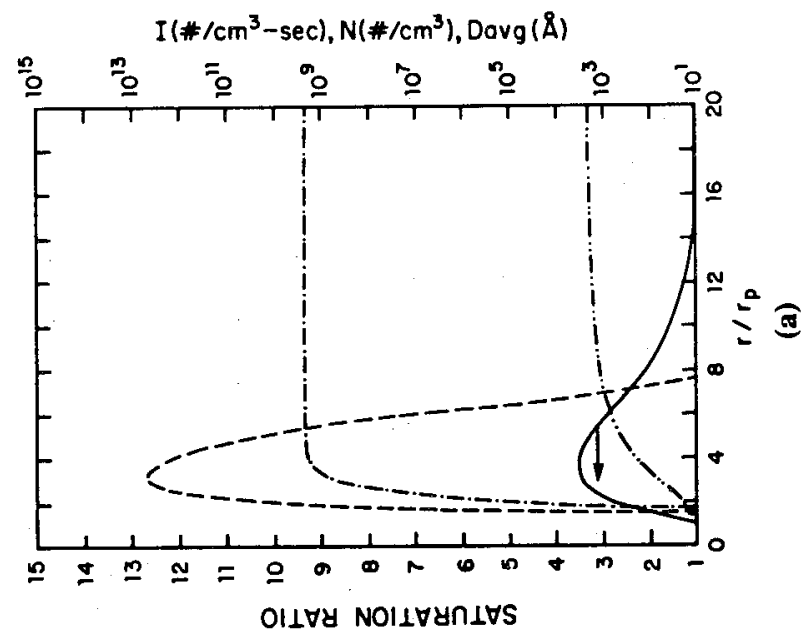




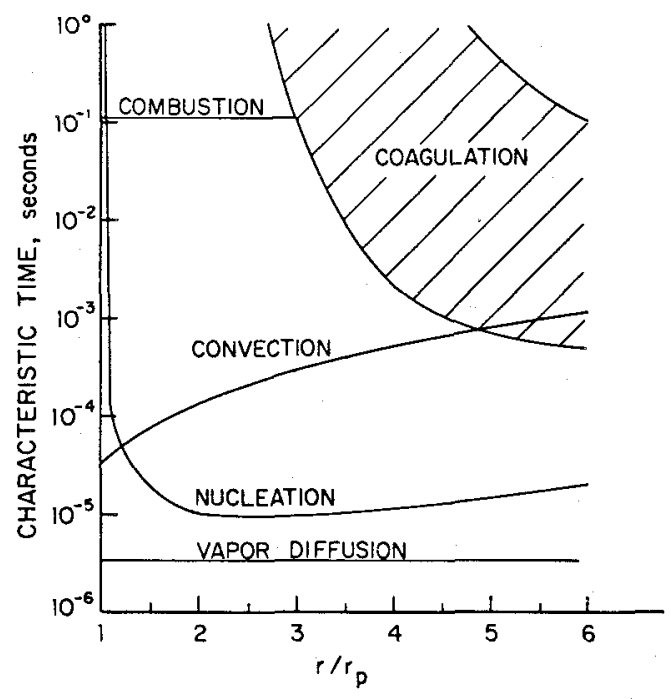

FIGURE 8. Characteristic times as a function of radial position at $64 \%$ burnout.

steady state with respect to combustion. The time required to establish a steady state for nucleation is at least an order of magnitude less than the characteristic convection time for $r / r_{\mathrm{p}}>2$. At smaller radial positions the nucleation rate is too small to be significant. The calculation of the nucleation rate by Eq. (6) assumes that there is a steady state distribution of molecular clusters. This assumption is justified in the regions where nucleation is important.

In the region where nucleation is important coagulation is too slow to have any effect on the aerosol size distribution. Figure 8 suggests that coagulation may become significant between five and ten radii from the coal particle. However, the addition of coagulation to the model would not alter the qualitative results: early nucleation of vapor followed by slow growth as the aerosol moves far from the particle's surface.

At the gas temperatures in the sample calculation, the mean free path in the gas is on the order of $0.5 \mu \mathrm{m}$. The results suggest that near the coal particle the aerosol is much smaller than the mean free path and therefore the use of the growth law in the free molecule regime is correct.
For radial positions greater than about ten particle radii, the average aerosol diameter approaches the mean free path length. In this region the free molecule growth law overpredicts the growth rate of aerosol particles. Therefore, if the transition from free molecule to continuum growth were included in the growth rate, the particles would not grow as fast as indicated by the calculations far away from the coal particle's surface.

At conditions typical of the sample calculation, the Kelvin effect is important for aerosol particles in the range of $1-5 \mathrm{~nm}$. By neglecting the Kelvin effect, we are overpredicting the growth rate for particles in this size range. Including the Kelvin effect would make the aerosol smaller on average while increasing the nucleation rate. That is, there would be less depletion of vapor by particles near the critical size and therefore more nucleation.

\section{CONCLUSIONS}

A mathematical model has been developed to describe the vaporization and condensation of ash in coal during combustion. The behavior of a single particle is studied in order to evaluate the influence of the local combustion environment on aerosol formation. A steady-state solution to the problem of aerosol transport and growth can be superimposed on the quasisteady combustion problem both because the time scales of the relevant processes are much shorter than the combustion time scale and because the concentration of vapor and aerosol is too small to affect combustion.

The local combustion environment has a large influence on both vaporization and aerosol formation. The radial convective velocity enhances the transport of vapor. Higher temperatures and a locally more reducing atmosphere increase the amount of ash vaporized. The steep gas temperature and composition gradients near the coal particle provide a strong driving force for nucleation and condensation. Certain properties of the ash strongly influence the nucleation rate and the aerosol size distribution. Therefore, the present relatively un- 
sophisticated calculation can be used to identify combustion conditions or ash species that are likely to produce a particular kind of aerosol.

The vaporization rate of ash is only weakly dependent on the presence of the aerosol in the gas, partly because of the convective transport (due to combustion) at the particle's surface. Detailed knowledge of the aerosol formation or growth processes is, therefore, not needed for the calculation of ash vaporization rates.

For refractory species like silica, nucleation occurs during combustion and takes place very near the coal particle. Nucleation is, therefore, controlled by the combustion process rather than by heat transfer from the combustion gases or other processes that follow combustion. Calculations indicate that coagulation does not become important until virtually all the nucleation has taken place. The results of these calculations may not be valid farther than from five to ten radii from the coal particle since we have neglected coagulation.

The results of this study cannot be used to predict absolutely the size distribution of submicron fly ash. However, they do begin to fill in some of the details of the overall process. Further work is needed to elucidate the relative importance of coagulation and condensation as mechanisms for ash particle growth. This study also reveals a need for better characterization of the high-temperature physical properties of ash and a better understanding of the factors that govern ash vaporization.

\section{REFERENCES}

Desrosiers, R. E., Riehl, J. W., Ulrich, G. D., and Chiu, A. S. (1979). 17th Symp. (Int.) on Combustion, Combust. Inst., Pittsburgh, pp. 1385-1433.

Dow Chemical Company, Thermal Research Laboratory
(1971). JANAF Thermochemical Tables (2nd ed.), National Bureau of Standards, Washington, DC.

Fehlberg, E. (1969). NASA Tech. rep. R-315.

Friedlander, S. K. (1977). Smoke, Dust, and Haze Fundamentals of Aerosol Behavior, Wiley, New York.

Gelbard, F. (1978). Ph.D. thesis, California Institute of Technology.

Kingery, W. D. (1959). J. Am. Ceram. Soc., 42:6-10.

Libby, P. A., and Blake, T. R. (1979). Combust. Flame 36:139-169.

Markowski, G. R., Ensor, D. S., Hooper, R. G., and Carr, R. C. (1980). Environ. Sci. Technol. 14:1400-1402.

McNallan, M. J., Yurek, G. J., and Elliot, J. F. (1981). Combust. Flame 42:45-60.

Mims, C. A., Neville, M., Quann, R. J., and Sarofim, A. F. (1980). In AIChE Symp. Ser. 201 (A. F. Engel, S. M. Slater, and J. W. Gentry, eds.), Am. Inst. Chem. Eng., New York.

Mitchell, R. E., and McLean, W. J. (1982). Application of two-color pyrometry to studies of pulverized fuel combustion, presented at Combust. Inst./Western States Section 1982 Spring Meeting, Salt Lake City, UT.

Mulcahy, M. F. R., and Smith, I. W. (1969). Rev. Pure Appl. Chem. 19:81-108.

Neville, M., Quann, R. J., Haynes, B. S., and Sarofim, A. F. (1980). 18th Symp, (Int.) on Combustion, Combust. Inst., Pittsburg, PA, pp. 1267-1274.

Quann, R. J., and Sarofim, A. F. (1982). Vaporization of refractory oxides during pulverized coal combustion, presented at 19th Symp. (Int.) on Combustion, Haifa, Israel.

Raask, E., and Wilkins, D. M. (1965). J. Inst. Fuel 38:255262.

Schick, H. L. (1960). Chem. Rev. 60:331-362.

Senior, C. L., and Flagan, R. C. (1982). A theoretical study of a single buming coal particle in an infinite quiescent medium, presented at Combust. Inst./Western States Section 1982 Spring Meeting, Salt Lake City, UT.

Smithells, C. J. (1976). Metals Reference Handbook, Butterworths, London.

Taylor, D. D. and Flagan, R. C. (1981). In ACS Symp. Ser. 167 (E. S. Macias and P. K. Hopke, eds.), Am. Chem: Soc., Washington, DC.

Wakeshima, H. (1954). J. Chem. Phys. 22:1614-1615.

Received 14 May 1982; accepted 8 September 1982 